\title{
Differences in skin lesions of endogenous and exogenous Cushing's patients
}

\author{
Fatma Erden ${ }^{1}$, Murat Borlu², Yasin Simsek ${ }^{3}$, Hasan Fahrettin Kelestemur ${ }^{3}$
}

${ }^{1}$ Department of Dermatology and Venereology, Ankara Occupational Diseases Hospital, Ankara, Turkey ${ }^{2}$ Department of Dermatology and Venereology, Faculty of Medicine, Erciyes University, Kayseri, Turkey ${ }^{3}$ Division of Endocrinology, Department of Internal Medicine, Faculty of Medicine, Erciyes University, Kayseri, Turkey

Adv Dermatol Allergol 2019; XXXVI (3): 272-275

DOI: https://doi.org/10.5114/ada.2018.74639

\begin{abstract}
Introduction: Cushing's syndrome is a rare condition characterized by increased glucocorticoid levels. Dermatologically, it causes a variety of skin conditions such as atrophy, striae, acne, plethora, hypertrichosis, hirsutism, acanthosis nigricans, hyperpigmentation, alopecia, purpura and fragile skin. Although skin lesions of Cushing's syndrome have been described, exogenous and endogenous types have not been studied in detail.

Aim: To determine differences in possible skin lesions depending on the cause of Cushing's syndrome.

Material and methods: A total of 35 patients - 16 iatrogenic Cushing's syndrome patients and 19 endogenous Cushing's syndrome patients - who were diagnosed in Erciyes University and 15 healthy individuals were included in this study.

Results: There was at least one skin finding in 34 (97.1\%) of the patients with Cushing's syndrome and 9 (60\%) in the control group $(p=0.001)$. Comparison regarding skin findings in patient and control groups revealed that hypertrichosis, hyperpigmentation, and fungal infections were significantly more frequent in the patient group than the control group. Hirsutism was found more frequently in the endogenous group whereas stria, hypertrichosis and fungal infections were more frequent in the exogenous group.

Conclusions: Since Cushing's syndrome is a rare disease and it is often diagnosed later in life, data on the frequency of skin findings are limited and sparse in the literature. In the comparison of endogenous Cushing's and exogenous Cushing's groups, acne, hypertrichosis, and fungal infections were found more frequently in the exogenous Cushing's group and hirsutism more frequently in the endogenous Cushing's group.
\end{abstract}

Key words: Cushing's syndrome, dermatological findings, exogenous Cushing's, endogenous Cushing's, skin alterations.

\section{Introduction}

Cushing' s syndrome (CS) is a rare condition characterized by increased glucocorticoid levels. This clinical picture may originate from excess production of glucocorticoids by the pituitary gland or adrenal gland (endogenous), as well as by ectopic secretion from other tissues or by cortisol-containing drug intake (exogenous) [1].

Increased glucocorticoid levels lead to proximal muscle weakness, opportunistic infections, osteopenia/ osteoporosis, cataract, hypertension, central obesity, moon face, menstrual problems, and psychological and cognitive changes [2-10]. In addition, dermatologically, it causes a variety of skin conditions such as atrophy, striae, acne, plethora, hypertrichosis, hirsutism, acanthosis nigricans, hyperpigmentation, alopecia, purpura and fragile skin [11, 12]. Seventy-three percent (329/448) of CS patients have been reported to have skin alterations in the European Registry on Cushing's syndrome' $s$ baseline demographic and clinical characteristics [13].

\section{Aim}

Although skin lesions of CS have been described, exogenous and endogenous types have not been studied in detail. In this study, our aim was to determine the possible differences of skin lesions depending on the cause of CS.

Address for correspondence: Fatma Erden MD, Department of Dermatology and Venereology, Ankara Occupational Diseases Hospital, Ankara Mesleki ve Çevresel Hastalıklar Hastanesi, Dermatoloji Kliniği Osmangazi Mahallesi Atlılar Caddesi No: 45, 06280 Keçiören, Ankara, Tukey, phone: +90 31258083 95, +90 506751 61 73, e-mail: doktor_ayyildiz@hotmail.com Received: 7.02.2018, accepted: 27.02.2018. 


\section{Material and methods}

The study was carried out between November 2012 and August 2013 in Erciyes University Faculty of Medicine Department of Dermatology and Venereal Diseases.

This study was approved by the Erciyes University Faculty of Medicine Ethics Committee (Ethics Committee Approval number: 2012/628). Volunteers involved in the study were given information about the procedures to be applied and written approval was obtained.

In this study, the patient group consisted of $16 \mathrm{pa}-$ tients with the diagnosis of pemphigus and alopecia totalis and who developed iatrogenic CS after systemic steroid treatment for at least 3 months $(0.5-1 \mathrm{mg} / \mathrm{kg} / \mathrm{day})$ at the Erciyes University Department of Skin and Venereal Diseases and 19 patients (35 patients in total) who were diagnosed with CS at the Erciyes University Department of Endocrine and Metabolism. Patients under 18 years of age and older than 65 years of age and patients who received treatment for the disease and achieved remission or were receiving treatment for this disease were not included in this study. The control group included 15 volunteers within the ages of 18-65 with no known and identified chronic disease.

Patients and controls were evaluated in terms of stria, acne, hirsutism, hypertrichosis, alopecia, ecchymosis, acanthosis nigricans and hyperpigmentation and present findings were recorded. Patients with endogenous CS and iatrogenic Cushing's were included in the study in the first period of diagnosis. The dermatological examinations of the patients were done in detail by the same doctor (FE). Acne severity was scored 0-3 (0: none, 1: mild, 2: moderate, 3: severe). The developing striae based on CS are pinker and wider, while the striae base on weight gain are paler and narrower. Taking this into account, the striae were evaluated according to their color: 0: none, 1: mild, 2: moderate and 3: severe [14]. Flexural areas such as axilla, inguinal, and neck were evaluated for acanthosis nigricans. For hyperpigmentation, the face region was evaluated together with the flexural areas. Alopecia was not typed. Hirsutism and hypertrichosis were recorded as either present or absent.

\section{Statistical analysis}

All statistical analyses were performed using the Statistical Package for Social Sciences (SPSS) 22 for Windows. The conformity of the data to the normal distribution was checked by the Shapiro-Wilk test. Measurable (quantitative) data were presented as mean \pm standard deviation. Variables that did not fit a normal distribution were expressed as median and minimum-maximum values. Student's t test was used to evaluate the difference between the patient and the control group for the normal distribution-matched data.

The $\chi^{2}$ test was used for the evaluation of categorical variables of the patients' and the control group's find- ings. The distribution of countable data is defined as \% (percent). In all tests $p$-values below 0.05 were considered statistically significant.

\section{Results}

\section{Demographic findings}

Of the 50 people who were included in the study, 35 belonged to the patient group and 15 belonged to the control group. In the patient group, 19 (54.2\%) patients had endogenous Cushing's whereas 16 (45.8\%) patients had exogenous Cushing's. Of the 50 people, 15 (30\%) were male and 35 (70\%) were female (Table 1). The mean age of patients with endogenous Cushing's, exogenous Cushing's and the control group was $43.6 \pm 11.1$, $45.5 \pm 14.1$ and $31.6 \pm 6.9$, respectively (Table 1 ).

There was at least 1 skin finding in 34 (97.1\%) of the patients with CS and 9 (60\%) in the control group ( $p=$ 0.001). The only case with no skin findings in patients with CS was in the endogenous group.

\section{Evaluation of skin findings of the control and the patient groups}

In comparison of patient and control group skin findings, hypertrichosis, hyperpigmentation and fungal infection were significantly more frequent in the patient group than in the control group (Table $2, p<0.05$ ). The frequency of skin tag lesions was significantly higher in the control group. There was no significant difference in other skin lesions (Table 2, $p>0.05$ ).

\section{Evaluation of skin findings between endogenous,} exogenous and control groups

In comparison of endogenous and exogenous groups' skin findings, frequency of hyperpigmentation was higher in the endogenous group than in the control group, whereas frequency of hypertrichosis, stria, hyperpigmentation and fungal infections was significantly higher in the exogenous group $(p<0.05)$. When endogenous and the exogenous groups were compared, there was a significant difference in stria, hirsutism, hypertrichosis and

Table 1. Age and gender distribution of control and patient groups

\begin{tabular}{lccc}
\hline Groups & $\begin{array}{c}\text { Male, } \\
n(\%)\end{array}$ & $\begin{array}{c}\text { Female, } \\
n(\%)\end{array}$ & $\begin{array}{c}\text { Mean age } \\
\text { (mean } \pm \text { SD) }\end{array}$ \\
\hline $\begin{array}{l}\text { Patients + control group } \\
(n=50)\end{array}$ & $15(30)$ & $35(70)$ & $40.6 \pm 12.5$ \\
\hline $\begin{array}{l}\text { Patients with Cushing's } \\
\text { syndrome }(n=35)\end{array}$ & $10(28.6)$ & $25(71.4)$ & $44.5 \pm 12.4$ \\
\hline Control group $(n=15)$ & $5(33.3)$ & $10(66.7)$ & $31.6 \pm 6.9$ \\
\hline Endogenous group $(n=19)$ & $5(26.3)$ & $14(73.7)$ & $43.6 \pm 11.1$ \\
\hline Exogenous group $(n=16)$ & $5(31.3)$ & $11(68.8)$ & $45.5 \pm 14.1$ \\
\hline
\end{tabular}


Table 2. Evaluation of skin findings of control and patient groups

\begin{tabular}{lccc}
\hline Skin findings & $\begin{array}{c}\text { Patient group } \\
(n=35) / n(\%)\end{array}$ & $\begin{array}{c}\text { Control group } \\
(n=15) / n(\%)\end{array}$ & $P$-value \\
\hline Stria & $11(31.4)$ & $0(0)$ & 0.014 \\
\hline Acne & $5(14.3)$ & 0 & $>0.05$ \\
\hline Hirsutism & $5(14.3)$ & $2(13.3)$ & $>0.05$ \\
\hline Hypertrichosis & $15(42.9)$ & 0 & 0.002 \\
\hline Alopecia & $10(28.6)$ & $2(13.3)$ & $>0.05$ \\
\hline Ecchymosis & $15(42.9)$ & $6(40)$ & $>0.05$ \\
\hline Hyperpigmentation & $11(31.4)$ & 0 & 0.014 \\
\hline Acanthosis nigricans & $4(11.4)$ & 0 & $>0.05$ \\
\hline Skin tag & $3(8.6)$ & $6(40)$ & $0.008^{*}$ \\
\hline Fungal infection & $19(54.3)$ & $1(6.7)$ & 0.002 \\
\hline
\end{tabular}

*Significantly higher in the control group.

fungal infection ( $p<0.05$, Table 3 ). While hirsutism was higher in the endogenous group, stria, hypertrichosis and fungal infections were higher in the exogenous group. The stria evaluation of the endogenous group was as follows: $84.2 \%$ had no striae (0), 5.3\% had moderate (2) striae and $10.5 \%$ had severe striae (3). These frequencies for the exogenous group were as follows: $50 \%$ had no striae (0), $37.5 \%$ had mild striae (2) and $12.5 \%$ had severe striae (3).

\section{Discussion}

Cushing's syndrome causes skin atrophy, stria, acne, plethora, hypertrichosis, hirsutism, acanthosis nigricans, hyperpigmentation, alopecia, purpura and many other dermatological conditions [11, 12].

Glucocorticoids cause acne and seborrhea by the proliferation of sebocytes. Glucocorticoids also reduce the synthesis of dermal collagen and collagenous tissue by regulating the expression of matrix metalloproteinase (MMP) and other tissue inhibitors and thereby cause striae and skin atrophy by this dermal scarring. Hypertrichosis and hirsutism are the result of glucocorticoids formed by androgenic receptors and adrenal androgen increase or cortisol increase on terminal and veil hair $[15,16]$.

In the European Registry on CS, the frequency of skin alteration was reported as 73.3\% (311/424) for endogenous CS and 75\% (18/24) for exogenous CS [13]. In our study, $97.1 \%$ of the patients with CS and $60 \%$ of the control group had at least 1 skin finding. In our study, the only patient without skin findings among the CS patients belonged to the endogenous group. The more frequent detection of skin findings in our study may be due to the detailed examination of skin findings by a dermatologist.

In a study of Stratakis et al. on 36 CS patients including children and adolescents between 6 and 21 years of age, striae were found in $77.7 \%$ of patients, acne in $58.3 \%$, hirsutism in 63.7\%, acanthosis nigricans in $27.7 \%$, ecchymosis in $27.7 \%$, hyperpigmentation in $16.6 \%$ and fungal infection in $11.1 \%$ [12].

In another study consisting of a total of 302 patients with 239 women and 63 men with CS, the results were reported as follows: acne and hirsutism $72 \%$, skin atrophy $62 \%$ and fungal infection 6\% [17].

In our study, fungal infection was found in $54.3 \%$ of patients, striae in $31.4 \%$, ecchymosis in $42.9 \%$, hypertrichosis in $42.9 \%$, hyperpigmentation in $31.4 \%$, alopecia in $28.6 \%$, acne in $14.3 \%$, hirsutism in $14.3 \%$ and acanthosis nigricans in $11.4 \%$. Compared to similar studies, striae, acne, acanthosis nigricans and hirsutism were less frequent; hyperpigmentation, ecchymosis and fungal infections were more frequent in our study [17]. Differences in skin finding frequencies can be attributed to similar studies being conducted on patients with free endog-

Table 3. Comparison of skin findings between endogenous/exogenous/control groups

\begin{tabular}{|c|c|c|c|c|c|c|}
\hline Skin findings & $\begin{array}{c}\text { Endogenous }(n=19) \\
n(\%)\end{array}$ & $\begin{array}{c}\text { Exogenous }(n=16) \\
n(\%)\end{array}$ & $\begin{array}{c}\text { Control }(n=15) \\
n(\%)\end{array}$ & $p 1$ & $p 2$ & p3 \\
\hline Stria & $3(15.8)$ & $8(50)$ & $0(0)$ & $>0.05$ & 0.001 & 0.03 \\
\hline Acne & $1(5.3)$ & $4(25)$ & 0 & $>0.05$ & $>0.05$ & $>0.05$ \\
\hline Hirsutism & $5(26.3)$ & 0 & $2(13.3)$ & $>0.05$ & $>0.05$ & 0.02 \\
\hline Hypertrichosis & $4(21.1)$ & $11(68.8)$ & 0 & $>0.05$ & $<0.0001$ & 0.005 \\
\hline Alopecia & $5(26.3)$ & $5(31.3)$ & $2(13.3)$ & $>0.05$ & $>0.05$ & $>0.05$ \\
\hline Ecchymosis & $7(36.8)$ & $8(50)$ & $6(40)$ & $>0.05$ & $>0.05$ & $>0.05$ \\
\hline Hyperpigmentation & $5(26.3)$ & $6(37.5)$ & 0 & 0.03 & 0.008 & $>0.05$ \\
\hline Acanthosis nigricans & $2(10.5)$ & $2(12.5)$ & 0 & $>0.05$ & $>0.05$ & $>0.05$ \\
\hline Skin tag & $2(10.5)$ & $1(6.3)$ & $6(40)$ & 0.04 & $<0.025$ & $>0.05$ \\
\hline Fungal infection & $4(21.1)$ & $15(93.8)$ & $1(6.7)$ & $>0.05$ & $<0.0001$ & $<0.0001$ \\
\hline
\end{tabular}

p1-Comparison of endogenous/control group, p2 - comparison of exogenous/control group, p3 - comparison of endogenous/exogenous group. 
enous CS and the duration of exposure to cortisone in exogenous Cushing's patients on our follow-up [14].

In the comparison of endogenous and exogenous groups, rates of acne, hypertrichosis, and fungal infections were found to be higher in the exogenous group and hirsutism was more frequent in the endogenous group.

In addition, compared to the control group, hyperpigmentation in endogenous Cushing's patients and hyperpigmentation, hypertrichosis, stria and fungal infections in the exogenous Cushing's patients were found to be more frequent. As we observed in our study, patients with endogenous Cushing's had been diagnosed late because it took a long time for the clinical findings to become apparent, but patients with the disease of exogenous origin were referred earlier with more prominent clinical findings.

The most important limitation of our study was that we could not evaluate the clinical state after the treatment of the patients in the endogenous group and after the cessation of steroid therapy and the cortisol levels returned to baseline levels in the exogenous group. Another drawback of the study was the lower average age of the volunteers in the control group. Finally, the fact that the study was conducted in a small group of patients and single-centered was another limitation for us.

\section{Conclusions}

Since CS is a rare disease and it is often diagnosed late, data on the frequency of skin findings are limited and sparse in the literature. The single-center case series consisted of a small number of patients, but a high number of cases has only been achieved in multicenter studies. Another difference in our study is that we included cases with exogenous CS, but also observed clinical differences between endogenous and exogenous CS patients in terms of dermatological findings. More detailed studies on this topic on larger numbers of cases with longer follow-ups will make a bigger contribution to knowledge of the issue.

\section{Conflict of interest}

The authors declare no conflict of interest.

\section{References}

1. Cushing $\mathrm{H}$. The basophil adenomas of the pituitary body and their clinical manifestations (pituitary basophilism). Johns Hopkins Hospital Bull 1932; 50: 137-95.

2. Birch WM. Endocrinology for the house officer. $3^{\text {rd }}$ ed. Williams \& Wilkins, Baltimore 1994; 186-9.

3. Aron DC, Findling JW, Tyrrell JB. Hypothalamus and pituitary. In: Basic \& Clinical Endocrinology. $5^{\text {th }}$ ed. Greenspan FS, Strewler GJ (eds.). Stamford, Conn: Appleton \& Lange 1997; 95-156.
4. Boumpas DT, Paliogianni F, Anastassiou ED, et al. Glucocorticosteroid action on the immune system: molecular and cellular aspects. Clin Exp Rheumatol 1991; 9: 413-23.

5. Bouzas EA, Mastorakos G, Friedman TC, et al. Posterior subcapsular cataract in endogenous Cushing syndrome: an uncommon manifestation. Invest Ophthalmol Vis Sci 1993; 34: 3497-500.

6. Ohmori N, Nomura K, Ohmori K, et al. Osteoporosis is more prevalent in adrenal than in pituitary Cushing's syndrome. Endocr I 2003; 50: 1-7.

7. Kaltsas GA, Korbonits M, Isidori AM, et al. How common are polycystic ovaries and the polycystic ovarian syndrome in women with Cushing's syndrome? Clin Endocrinol (Oxf) 2000; 53: 493-500.

8. Horiba N. Sexual and gonadal dysfunction in adrenal disorders. Nihon Rinsho 1997; 55: 2979-84.

9. Contreras LN, Masini AM, Danna MM, et al. Glucocorticoids: their role on gonadal function and LH secretion. Minerva Endocrinol 1996; 21: 43-6.

10. Starkman MN, Schteingart DE. Neuropsychiatric manifestations of patients with Cushing's syndrome. Relationship to cortisol and adrenocorticotropic hormone levels. Arch Intern Med 1981; 141: 215-9.

11. Kirk LF Jr, Hash RB, Katner HP, et al. Cushing's disease: clinical manifestations and diagnostic evaluation. Am Fam Physician 2000; 62: 1119-27, 1133-4.

12. Stratakis CA, Mastorakos G, Mitsiades NS, et al. Skin manifestations of Cushing disease in children and adolescents before and after the resolution of hypercortisolemia. Pediatr Dermatol 1998; 15: 253-8.

13. Valassi E, Santos A, Yaneva M, et al. The European Registry on Cushing's syndrome: 2-year experience. Baseline demographic and clinical characteristics. Eur J Endocrinol 2011; 165: 383-92.

14. Yanovski JA, Cutler GB Jr. Glucocorticoid action and the clinical features of Cushing's syndrome. Endocrinol Metab Clin North Am 1994; 23: 487-509.

15. Chedid M, Hoyle JR, Csaky KG, et al. Glucocorticoids inhibit keratinocyte growth factor production in primary dermal fibroblasts. Endocrinology 1996; 137: 2232-7.

16. Haapasaari KM, Risteli J, Oikarinen A. Recovery of human skin collagen synthesis after short-term topical corticosteroid treatment and comparison between young and old subjects. Br J Dermatol 1996; 135: 65-9.

17. Boscaro M, Barzon L, Fallo F, et al. Cushing syndrome. Lancet 2001; 357: 783-91. 